\title{
JOHANNES THESSELIUS IN NJEGOVA ZBIRKA PLESOV ZA PETGLASNI INŠTRUMENTALNI SESTAV
}

Zbirka Neue liebliche Paduanen, Intraden und Galliarden auff allerley Instrumenten zu gebrauchen mit fünff Stimmen componirt Johannesa Thesseliusa, je v zgodovini glasbe zapisana kot najzgodnejšo delo oblikovano $v$ smislu variacijskih suit $^{2} \mathrm{za}$ inštrumentalni sestav. Vsebuje trideset plesov, razporejenih $\mathrm{v}$ desetih ciklih po vedno enakem zaporedju treh plesov Paduana - Intrada - Galliarda. Natisnjena je bila v letu 1609, pri založniku in tiskarju Paulu Kauffmannu ${ }^{3}$ v Nürnbergu. Plese v Thesseliusovi suiti povezuje ista tonaliteta, medtem ko je variacijsko oblikovanje na posameznih mestih le nakazano. Variacijska suita za inštrumentalni sestav ali krajše ansambelska variacijska suita je bila kratkotrajen pojav v avstrijsko-nemški glasbi na začetku 17. stoletja, ali natančneje med 1609 in 1618, ko so izšle štiri plesne zbirke naslednjih avtorjev - Johannesa Thesseliusa, Paula Peuerla, Johanna Hermanna Scheina in Isaaca Poscha (tabela 1).

\footnotetext{
'Izvirni naslov zbirke se glasi: Neue liebliche Padua=// nen / Intraden und Galliarden /// auff allerley Instiumenten zu gebrau=// chen / mit fünff Stimmen com= // ponit // durch // Johannem Thesselium // Musicum \& c. // TENOR. // Gedruckt zu Nümberg / bey vnd in ver=// legung Paul Kauffmanns // MDCIX. Thesseliusova zbirka plesov je bila v celoti prestavljena $\mathrm{v}$ obliko partiture po mikrofilmskih kopijah omenjenega izvirnega tiska, $\mathrm{v}$ diplomski nalogi avtorice članka $\mathrm{z}$ naslovom Transkripcija in analiza inštrumentalne zbirke plesov za pet glasov Johannesa Thesseliusa, na Oddelku za muzikologijo Filozofske fakultete, Ljubljana 1998; do sedaj je iz zbirke v transkripciji izšel le četrti cikel treh plesov (št. X, XI, XII), vendar brez redakcijskih pojasnil, v Zeitschrif für Spielmusik (614/615), Hrsg. Volker Roth. Celle, Moeck Verlag 1990

${ }^{2}$ Opredeljevanje kot "variacijske" je problematično pri vseh štririh avtoriih ansambelske variacijske suite, ker ne moremo govoriti o očitni ritmični ali melodični povezanosti med plesi, Metoda Kokole, Inštrumentalna zbirka Musicalische Ehrenfreudt (1618) skladatelja Isaaca Poscha, Muzikološki zbornik XXXII, Ljubljana, Oddelek za muzikologijo Filozofske fakultete 1996, str. 24.

${ }^{3}$ Paul Kauffmann (1568-1632) je bil protestantski založnik in tiskar, ki je tiskal tudi dela Valentina Hausmanna, Hansa Lea Hasslerja, Johanna Stadena in dela drugih skladateljev ansambelske plesne glasbe na prehodu iz 16. v 17.stoletje, M. Kokole, Isaac Posch in njegova inštrumentalna dela; $s$ posebnim ozirom na variacijske suite za inštrumentalni sestav zbirke Musicalische Ehrenfreudt (1618), magistrsko delo, Oddelek za muzikologijo FF, Ljubljana 1995, str. 50.
} 
Tabela 1: Avtorji inštrumentalne variacijske suite

\begin{tabular}{|c|c|c|c|}
\hline $\begin{array}{l}\text { Johannes } \\
\text { THESSELIUS }\end{array}$ & $\begin{array}{l}\text { Paul } \\
\text { PEUERL }\end{array}$ & $\begin{array}{l}\text { Johann Hermann } \\
\text { SCHEIN }\end{array}$ & $\begin{array}{l}\text { Isaac } \\
\text { POSCH }\end{array}$ \\
\hline $\begin{array}{l}1609 \\
\text { Nümberg / } \\
\text { P. Kauffmann }\end{array}$ & $\begin{array}{l}1611 \\
\text { Nürnberg / } \\
\text { A. Wagenmann }\end{array}$ & $\begin{array}{l}1617 \\
\text { Leipzig / } \\
\text { A. Lamberg, C. Kloseman }\end{array}$ & $\begin{array}{l}1618 \\
\text { Regensburg / } \\
\text { M. Mylius }\end{array}$ \\
\hline Aschach ob der Enns & Steyr & Leipzig & Klagenfurt \\
\hline skladatelj na gradu & protest. mestni organist & kantor v Tomaževi cerkvi & stanovski organist \\
\hline $\begin{array}{l}3 \text { stavčna suita: } \\
\text { Paduana - Intrada Galliarda }\end{array}$ & $\begin{array}{l}\text { 4 stavčna suita: } \\
\text { Padouan - Intrada - Dantz - Galliarda }\end{array}$ & $\begin{array}{l}\text { 5staučna suita: } \\
\text { Padouan - Gagliarda - Courente } \\
\text { Allemande - Tripla }\end{array}$ & $\begin{array}{l}3 \text { stavčna suita: } \\
\text { Gagliarda (Couranta) - Tanz -Proportio }\end{array}$ \\
\hline 10 suit (30 plesov) za 5 glasov & 10 suit (40 plesov) za 4 glasove & 20 suit (100 plesov) za 5 glasov & 15 suit $(30$, oz. 45) za 5,4 glasove \\
\hline $\begin{array}{l}\text { "Neue lieblicbe Paduanen, } \\
\text { Intraden und Galliarden..." }\end{array}$ & $\begin{array}{l}\text { "Neue Padovan, Intrada, } \\
\text { Däntz unnd Galliarda" }\end{array}$ & "Banchetto musicale" & "Musicalische Ebrenfreudt" \\
\hline
\end{tabular}

Thesseliusovo življenje je bilo skrivnostno. Ne poznamo niti letnici rojstva in smrti, niti podatkov o skladateljevem glasbenem šolanju. Thesseliusova zbirka plesov za inštrumentalni ansambel in posvetilo v njej sta tako edina vira o njegovem glasbenem delovanju in ustvarjanju. Domnevamo lahko, da je pred natisom omenjene zbirke plesov deloval na gradu Aschach ob der Enns, ob desnem pritoku Donave pri mestu Enns (slovensko Aniža) kot glasbenik, saj si je v posvetilu baronu Carlu Jörgerju, kateremu je namenil svojo zbirko plesov, pripisal naziv "Musicus". ${ }^{4}$

Thesseliusovo zbirko plesov za inštrumentalni sestav je prvi omenil Georg Draudius, ${ }^{5} \mathrm{ki}$ je v bibliografiji $\mathrm{z}$ naslovom Bibliotheca classica, $\mathrm{v}$ revidirani izdaji iz leta 1625 , zabeležil še drugo Thesseliusovo zbirko, ki pa se ni ohranila. ${ }^{6}$ To je bila zbirka triglasnih motetov z naslovom Tricinia sacra, ${ }^{7}$ natisnjena na Dunaju leta 1615. Naslednji avtor, ki navaja Thesseliusa, je bil Fétis (1784-1871), vendar je v svoji biografiji glasbenikov le povzel prejšnji vir. Tako omenja le obe Thesseliusovi zbirki; kot prvo delo navaja zbirko plesov iz leta 1609 in kot drugo, zbirko triglasnih motetov iz leta 1615.

\footnotetext{
† Herald Kümmerling, Thesselius Johannes, Die Musik in Geschichte und Gegenwart 13, Kassel, Bärenreiter 1966, str. 330.

${ }^{5}$ Georg Draudius (1573-1635) je bil nemški bibliotekar, ki je bil v svojem času poznan po številnih teoloških spisih in delih o aristoteljski filozofiji, danes pa predvsem po vestnem zapisovanju bibliografij, ki so postale pomemben vir za proučevanje glasbene preteklosti. O glasbi govorijo tri njegove Bibliografije, vse tri tiskane v Frankfurtu:

Bibliotheca exotica... (1610, rev. 2/1625)

Bibliotheca classica...(1611, rev. 3/1625)

Bibliotheca librorum...(1611, rev. 2/1625), M.E.C. Bartlet, Georg Draudius, The new Grove Dictionary of Music and Musicians 5, Ed. S. Sadie, London 1980, str. 610-611.

${ }^{6}$ Friedrich Baser, Thesselius, Johann, The new Grove Dictionary of Music and Musicians 18, Ed. S. Sadie, London 1980 , str. 763.

- Tricinia sacra (Collection de motets a trois voix); Vienne, 1615, F. J. Fétis, Biographe universalle des Musiciens, culture et civilisation, Bruxelles (?) 1966, str. 212.
} 
Friedrich Baser $^{8}$ povezuje skladateljevo usodo z zaroto Wallenstein, ${ }^{9}$ ki se je verjetno pletla tudi na gradu njegovega delovanja. Grad je pripadal družini Harrach, vendar je grof Karl von Harrach preživel večino časa na Dunaju kot eden vodilnih svetnikov cesarja Ferdinanda II. Na gradu, ki je bil v oskrbi Thesseliusovega delodajalca, barona Carla Jörgerja, sta odraščali tudi dve Harrachovi hčeri. Verjetno je Thesselius dekleti poučeval glasbo in skrbel na gradu za zabavo in ples. Friedrich Baser pojasnjuje, ${ }^{10}$ da je bil zaradi poroke Harrachovih hčera $z$ Wallensteinom in grofom Terzkyjem, njegovim pristašem, v zaroto vpleten tudi njun učitelj. Verjetno je Thesseliusa doletel podoben konec kot Wallensteina in grofa Adama Terzkyja, saj je za imenovano zbirko triglasnih motetov, kot tudi za Thesseliusom samim, bila izbrisana vsakršna sled, hkrati pa tudi podatki o skladateljevem življenju. Prav tako se po dosedanjih popisih niso ohranili Thesseliusovi notni rokopisi. V izvirnem tisku iz leta 1609 so se ohranili posamezni glasovni zvezki ${ }^{11}$ zbirke plesov $\mathrm{v}$ enem samem izvodu, ki ga sedaj hrani glasbeni oddelek Saške deželne knjižnice v Dresdnu, pod signaturo Mus, 1-B-164-2. Ali je bil v politično zaroto v letu 1634 Thesselius resnično vpleten, pa nam do podrobnejše raziskave o njegovem poreklu in življenju, ostaja nepojasnjeno.

$\mathrm{V}$ natisu se je ohranila še ena Thesseliusova skladba, z naslovom Carmen musicum ... quinqu: vocibus compositum. Natisnil jo je Valentin am Ende v Leipzigu leta $1605^{12}$ in je Thesseliusova najzgodnejša tiskana skladba. Priložnostna vokalna skladba, ki je bila namenjena za poroko Heinricha Schwalenbergerja in Anne Zimmermann, se ni ohranila v celoti; od petih glasov so ostali le trije: I., II. sopran in tenor. ${ }^{13}$

Cikli treh plesov Johannesa Thesseliusa, kot tudi drugi podobni plesni cikli renesančnega in baročnega časa, se navezujejo na starejšo prakso združevanja plesov v pare. V našem primeru je iz preteklosti prevzeta plesna dvojica paduana - galliar$\mathrm{da}, \mathrm{v}$ katero je Thesselius vrinil tretji ples intrado. Rudolf Flotzinger navaja

\footnotetext{
${ }^{8}$ Friedrich Baser, Thesselius, Johann, The new Grove Dictionary of Music and Musicians 18, Ed. S. Sadie, London 1980, str. 763.

9 Albrecht Wallenstein (1584-1634) je bil vojvoda in vojskovodja iz plemiške rodbine na Češkem; v 30-letni vojni 1625 je najel vojsko za cesarja Ferdinanda II. in jo vzdrževal z davki iz zasedenih ozemelj in je bil pri tem zelo uspešen. Vendar ga je cesar 1630 odpustil in ga že 1632 znova poklical, da bi zadržal prodiranje Gustava Adolfa. Wallenstein pa se je začel samovoljno pogajati s Švedsko in nemškimi protestanti za sklenitev miru; bil je odstavljen kot veleizdajalec in umorjen, Leksikon CZ, Ljubljana 1973, str. 1047.

${ }^{10}$ Friedrich Baser, Thesselius, Johann, The new Grove Dictionary of Music and Musicians 18, Ed. S. Sadie, London 1980, str. 763.

"Posamezni izvirni glasovni zvezki v velikosti $15 \times 20 \mathrm{~cm}$ so zvezani v naslednjem zaporedju: tenor, cantus, basis, altus in quintavox. Vsak zvezek ima svojo naslovnico in enako uvodno posvetilo. Notni deli glasovnih zvezkov tenor, altus in quintavox obsegajo sedemnajst strani, notna dela glasovnih zvezkov cantus in basis pa eno stran več. Zvezki nimajo oštevilčenih strani, vendar so skladbe oštevilčene z rimskimi številkami. Nenavadno je, da zbirka nima za tisti čas običajnega nagovora izvajalcem, hvalnih pesmi in kazala.

${ }^{12}$ Répertoire international des sources Musicales (RISM), Einzeldrucke vor 1800, Band 8, Redaktion O. E Albrecht, K. Schlager, Kassel (etc.), Bärenreiter 1980, str. 346.

${ }^{13}$ Ibid., str. 346
} 
Thesseliusove cikle plesov kot primer tristavčne suitne oblike, ${ }^{14}$ vendar jih lahko razumemo tudi kot razširjene plesne pare - trojice plesov, saj se je suita v tem času šele oblikovala. Razširitev plesne dvojice prvič zasledimo v letu 1508, ko je Petrucci izdal zbirko za lutnjo, ${ }^{15} \mathrm{v}$ kateri je redaktor Dalza plesnemu paru pavane in saltarella dodal pivo. V 16. stoletju je bil osnovni ples največkrat pavana, kateri je sledil razgibani saltarello, v 17. stoletju pa je bil pogostejši par pavana - galliarda. Osnova plesnih dvojic, npr. paduane - galliarde je bila metrična sprememba iz dvo- v tridobnost. ${ }^{16}$ Princip ritmičnega kontrasta med plesno dvojico je bil zelo pomemben, vendar se $\mathrm{z}$ vrinjenim plesom intrado, pri Thesseliusu ni ohranil. Postavlja se vprašanje, zakaj Thesselius ni ohranil ritmičnega kontrasta počasne dvodobne paduane in hitre tridobne galliarde. Dejstvo je, da bi se $z$ vsakim vrinjenim plesom zmanjšal prvotni ritmični kontrast osnovne dvojice, Thesselius pa je izbral dvodobno intrado. S tem je v notnem zapisu nakazal, da mu v oblikovanju plesnega cikla ritmični kontrast ni bil najpomembnejši, kar pojasnuje rahljanje tedaj dobro utrjene plesne dvojice in premikanje v smeri suitnega oblikovanja samostojnih plesov. Vendar obstaja možnost, da so ritmični kontrast $\mathrm{v}$ izvajalski praksi ohranili, saj je bilo običajno, da so izvajalci sami plesom dodali poples, v katerem je šlo zgolj za ritmično spremembo iz dvo v tridobnost. Tako bi si v razširjeni Thesseliusovi suiti lahko sledili: dvodobna Pavana $s$ tridobnim poplesom, dvodobna Intrada in tridobna Galliarda.

Glasba za ples je vedno sledila enostavni in jasni ritmični strukturi, tako da plesalce ni zavajala $\mathrm{k}$ pozornemu poslušanju. Thesseliusova glasba je bila namenjena tudi za poslušanje, ob polni mizi, pri kakršni je bilo poslušanje po gradovih običajno in kar je v posvetilu skladatelj tudi omenil. ${ }^{17} \mathrm{~S}$ tem je njegova zbirka plesov lahko presegla glasbo namenjeno zgolj za ples in postala umetelnejša. Še posebej je premik v smeri stilizacije plesa opazen v intradi, ki koreografsko ni bila tako zahteven ples kot galliarda, zato je bila (že) pri Thesseliusu oblikovana $v$ smislu inštrumentalne skladbe. Intrade so v cikle plesov vključili še Peuerl, Haussmann, ${ }^{18}$ Hassler, ${ }^{19}$ Franck $^{20}$ in Widmann ${ }^{21}$.

\footnotetext{
${ }^{14}$ Rudolf Flotzinger, Geschichte der Musik in Österreich, Graz, Styria 1988, str. 86-87.

${ }^{15}$ Intabolatura de lauto, Libro quarto, Benetke, Petrucci 1508.

${ }^{16}$ Metoda Kokole, Isaac Posch in njegova inštrumentalna dela; s posebnim ozirom na variacijske suite za inštrumentalni sestav zbirke Musicalische Ehrenfreudt (1618), magistrsko delo, Ljubljana, Oddelek za muzikologijo FF, 1995, str. 54.

1: "wie man sie pflegen von E. G. Tafel zu Musiciren" (glej prilogo št. 1)

${ }^{18}$ Neue Intrade..., Nürnberg 1602, 1603, 1604.

${ }^{19}$ Lustgarten neuer teutscher Gesäng, Balleti, Galliarden und Intraden, Nürnberg 1601.

${ }^{20}$ Newe Pavanen, Galliarden und Intraden, a 4, 5 \& 6, Coburg 1603.

${ }^{21}$ Gantz neue Cantzon, Intraden, Balletten, Courranten, a 4, Nürnberg 1613.
} 
Prve variacijske suite so se sicer pojavile v italijanski lutenjski glasbi 16 . stoletja, ${ }^{22}$ vendar jih kot solistične skladbe moramo ločevati od ansambelskih. Priprava za nastanek ansambelske variacijske suite je tako segla $v$ 16. stoletje, $v$ italijanski način združevanja plesov, ki je vplival na nemško lutenjsko glasbo ${ }^{23} \mathrm{v} 2$. polovici 16. stoletja. ${ }^{24}$ Poleg italijanskega vira so za ansambelsko variacijsko suito pomembni tudi angleški glasbeniki, ki so od zadnjega desetletja 16. stoletja delovali v severni Evropi. ${ }^{25} \mathrm{Z}$ njihovim vplivom se je iz nemške lutenjske glasbe na prelomu stoletja v Nemčiji razvila glasba za inštrumentalni sestav, iz tega pa se je izoblikovala ansambelska variacijska suita. ${ }^{26}$ Vzroka za nastanek ansambelske oblike prav na južno-nemškem področju sta bila v močni tradiciji inštrumentalne glasbe v nemških mestih in dejstvo, da je bil ples, za razliko od Italije, Francije in Anglije, kjer so ga gojili na dvorih v plemiških krogih, na Nemškem močno prisoten tudi med meščanstvom. ${ }^{27} \mathrm{~V}$ nemško-govorečih deželah (in tudi pri nas) so že od srednjega veka naprej, za izvajanje plesne glasbe med gostijami in porokami skrbela mestna in deželna cehovska združenja poklicnih glasbenikov. ${ }^{28}$

Za začetnika ansambelske variacijske suite, za katero je značilno, da se morajo stavki med seboj vsaj deloma povezovati $z$ enakimi motivičnimi deli ali začetki, velja Paul Peuerl (1611), ${ }^{29}$ ki je kot Thesselius deloval na današnjem območju Avstrije. Vendar lahko njene zametke nakažemo že pri Thesseliusu, predvsem v prvih dveh suitah (povezava začetka Intrade in Galliarde), v četrti (povezava basovega postopa Paduane in Galliarde) in $v$ peti suiti (povezava enega motiva $v$ Intradi in Galliardi).

\footnotetext{
${ }^{22}$ Najpomembnejši avtorji lutenjske variacijske suite so bili Antonio Casteliono, Antonio Rotta, Francesco da Milano in Paulo Borrono, Metoda Kokole, Isaac Posch in njegova inštrumentalna dela; s posebnim ozirom na variacijske suite za inštrumentalni sestav zbirke Musicalische Ehrenfreudt (1618), magistrsko delo, Ljubljana, Oddelek za muzikologijo FF, 1995, str. 41.

${ }^{23}$ Hans Neusidler, Ein newgeordnet künstlich Lautenbuch, Nürnberg 1536; Rudolf Wyssenbech, Tabulatubuch uff die Lutten, Zürich 1550; Hans Gerle, Ein newes sebr-künstlich Lautenbuch, Nürnberg, 1552; Hans Jacob Wecker, Tenor Lautenbuch vonn mancherley schönen und lieblichen Stucken mitt zweyen lauten zusammen zu schlagen, italienische Lieder; Pass'emezi, Saltarelli, Paduane: ueiter frantzösische, teütsche, mitt sampt mancherley däntzen, Basel 1552: Elias Nikolaus Ammerbach, Orgel oder Instrument Tabulatur; Leipzig 1571; Matthäus Waissel, Tabulatura per Matthaeum Waisselium Bartisteunensam Borussum, Frankfurt ob der Oder 1573; Melchior Neusidler, Teütsch Lautenbuch, Strasbourg 1574.

${ }^{24}$ Metoda Kokole, Isaac Posch in njegova inštrumentalna dela; s posebnim ozirom na variacijske suite za inštrumentalni sestav zbirke Musicalische Ehrenfreudt (1618), magistrsko delo, Ljubljana, Oddelek za muzikologijo FF, 1995, str. 28

${ }_{25}$ William Brade, Newe auserlesene Paduanen, Hamburg 1609; Thomas Simpson, Opusculum Newer Pavanen, Galliarden, Couranten unnd Volten, a 5, Frankfurt am Main 1610.

${ }^{26}$ Metoda Kokole, Isaac Posch in njegova inštrumentalna dela; s posebnim ozirom na variacijske suite za inštrumentalni sestav zbirke Musicalische Ehrenfreudt (1618), magistrsko delo, Ljubljana, Oddelek za muzikologijo FF, 1995, str. 28-29.

2: Metoda Kokole, Inštrumentalna zbirka Musicalische Ehrenfreudt (1618) skladatelja Isaaca Poscha, Muzikološki zbornik XXXII, Ljubljana, Oddelek za muzikologijo Filozofske fakultete 1996, str. 11.

${ }^{28}$ Metoda Kokole, Isaac Posch in njegova inštrumentalna dela; s posebnim ozirom na variacijske suite za inštrumentalni sestav zbirke Musicalische Ehrenfreudt (1618), magistrsko delo, Ljubljana, Oddelek za muzikologijo FF, 1995, str. 40.

${ }^{29}$ R. Flotzinger, G. Gruber, Musikgeschichte Österreichs: Von den Anfangen zum Barok, 2. izdaja, Wien (etc.), Böhlau 1995, str. 86-87.
} 
Thesseliusove Pavane, Intrade in Galliarde so oblikovane v treh delih s ponovitvijo. Izjema je le Intrada v deveti suiti, ki ima štiri-dele (glej prilogo št. 2). Največkrat se srednji del razlikuje od obeh objemajočih, čeprav tretji del ni ponovitev prvega, ampak se nanj samo navezuje. Vseh deset Pavan ima enako število taktov (48) kot tudi enako tri-delno členjenje po 16 taktov. Pri skladbah namenjenih za ples je skorajda brez izjeme veljalo pravilo o dvo, štiri, šest ali osemtaktnih periodah. ${ }^{30}$ Pri Intradah, kot tudi pri Galliardah pa se število taktov spreminja (glej prilogo št. 2). Vendar variabilnost števila taktov $\mathrm{v}$ Thesseliusovih Intradah in Galliardah ne zanika njune plesne funkcije. Dvorjani, ki so ples utrjevali vsak dan, so bili sposobni k osnovni koreografiji dodati ali skrčiti plesne figure ali izvesti dodatne improvizirane korake, poklone in podobno ${ }^{31}$ brez posebnega napora. Tudi v zbirki suit Paula Peuerla so imeli posamezni deli različno število taktov. ${ }^{32}$

Drugače pa je bilo z uporabo predtakta. Peuerlove Pavane so se začele na prvo dobo, medtem ko so plesi, ki so ji sledili, Intrada, Dantz in Galliarda, vedno bili oblikovani s predtaktom. ${ }^{33}$ Predtakt je plesalcu pomenil znak za začetek koraka, ki se je končal na prvo dobo in je imel podobno funkcijo kot pri pevcu vdih. Karl Garlinger je v predgovoru k Peuerlovim suitam zapisal, da je "Paduana kot prosta uvertura otvarjala cikel". ${ }^{34} \mathrm{~V}$ tem pogledu Peuerlove Pavane niso pomenile glasbe namenjene za ples, ampak so kot inštrumentalni uvodi le naznanjale začetek plesa. Drugače je bilo v Thesseliusovi zbirki, kjer so se vsi plesi začenjali na prvo dobo ${ }^{35}$ razen Intrade $\mathrm{v}$ deseti suiti. Tako umanjkanje predtakta tako postane argument, ki zagovarja neplesno funkcijo Thesseliusove zbirke plesov. Tudi ritmičnih sprememb $\mathrm{v}$ okviru enega plesa, kar bi spominjalo na ostanke renesančnih plesov, ${ }^{36}$ je bilo v Thesseliusovi zbirki malo. Ritmični spremembi iz dvo v tri-dobnost sta nastopili le dvakrat in sta trajali od tri do deset taktov.

Inštrumentalna glasba je bila na prehodu iz 16. v 17. stoletje sprva le prenos vokalne glasbe na inštrumente in se je od besede šele postopoma osamosvajala. Povsem drugače pa se je glasba namenjena plesu od vsega začetka razvijala neodvisno od vokalne. Zanikala je veljavna načela starih cerkvenih modusov, ki se jih je vokalna le počasi otresala in so pustili močan pečat celo na inštrumentalnih

\author{
30 Metoda Kokole, Inštrumentalna zbirka Musicalische Ehrenfreudt (1618) skladatelja Isaaca Poscha, Muzikološki zbornik XXXII, \\ Ljubljana, Oddelek za muzikologijo Filozofske fakultete 1996, str. 12. \\ 31 Ibid., str. 12. \\ 32 Diether de la Motte, Melodie, Kassel , Bärenreiter 1993, str. 222 \\ 33 Ibid., str. 223 \\ 34 Ibid., str. 220 \\ $35 \mathrm{~V}$ izvirniku menzurnih črt oziroma taktnic ni.
}

$36 \mathrm{M}$. Kokole, Issac Posch in njegova inštrumentalna dela; s posebnim ozirom na variacijske suite za inštrumentalni sestav zbirke Musicalische Ehrenfreudt (1618), magistrsko delo, Ljubljana, Oddelek za muzikologijo FF, 1995, str. 15. 
zvrsteh, ki so se v 16. stoletju razvijale po zgledu vokalnih. ${ }^{37}$ Tudi Thesseliusova zbirka plesov ne kaže navezovanje na vokalno glasbo in njen retoričen princip. Njegove suite so že imele značilnosti inštrumentalne glasbe. Glavni princip Thesseliusovega oblikovanja glasbe je bilo delo $\mathrm{z}$ motivi, ki jih je predvsem ritmično ponavljal. Podobno kot pri Poschu, tudi pri Thesseliusu motivična gradnja nikoli ni prerastla $\mathrm{v}$ kompleksnejše melodične fraze.$^{38}$ Za njegove plese še ni bilo značilno variiranje, razširitev, delitev ali oženje motiva, kar je nastopilo na posameznih mestih bolj kot izjema. Največkrat je motiv v vseh glasovih hkrati ritmično enako ponovil ali ga imitacijsko prenašal skozi vse glasove. (primeri 1, 2, 3). Manj je bilo sekvenčnih ponovitev motiva (primer 4) in daljših imitacij (primer 5).

\section{Primer 1}

Johannes Thesselius: Neue liebliche Paduanen, Intraden und Galliarden (1609); I. Paduana, srednji del (takti 25-29)

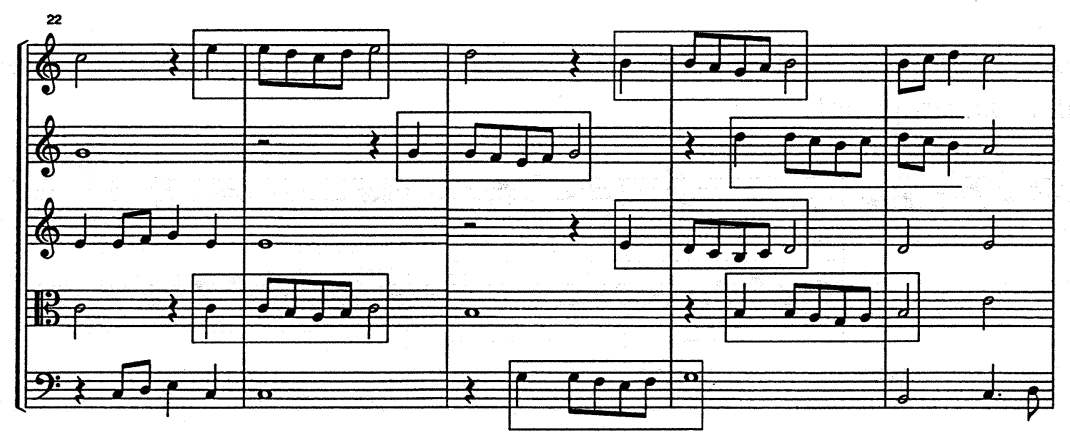

Primer 2

Johannes Thesselius: Neue liebliche Paduanen, Intraden und Galliarden (1609); II. Intrada (takti 22-25)

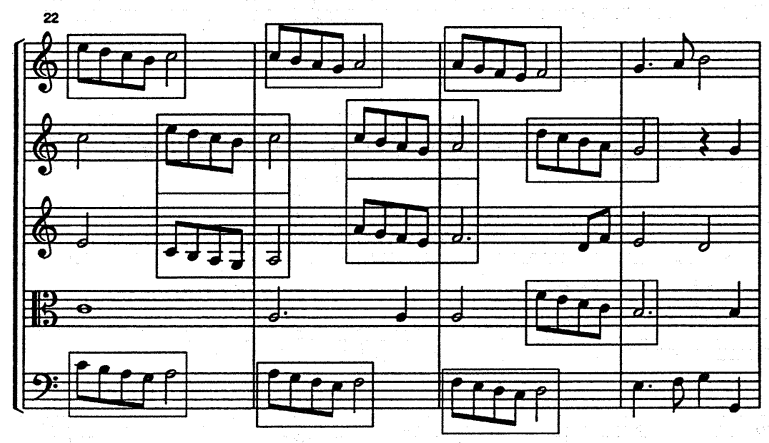

37 Metoda Kokole, Inštrumentalna zbirka Musicalische Ehrenfreudt (1618) skladatelja Isaaca Poscha, Muzikološki zbornik XXXII, Ljubljana, Oddelek za muzikologijo Filozofske-fakultete 1996, str. 25.

38 Ibid., str. 14. 
Primer 3

Johannes Thesselius: Neue liebliche Paduanen, Intraden und Galliarden (1609); II. Intrada (takti 26-29)

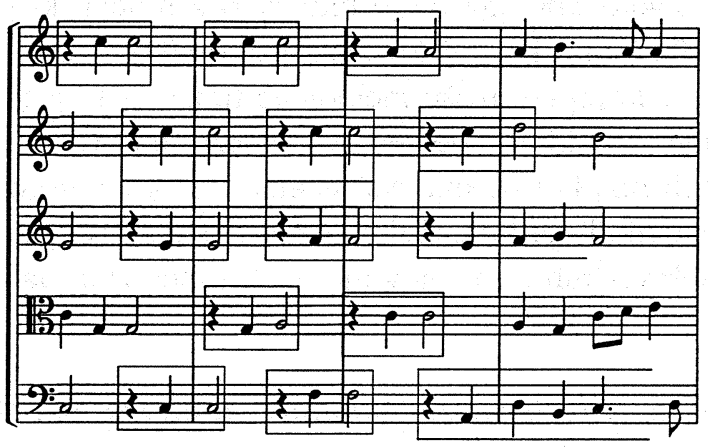

Primer 4

Johannes Thesselius: Neue liebliche Paduanen, Intraden und Galliarden (1609); IX. Galliarda, drugi del
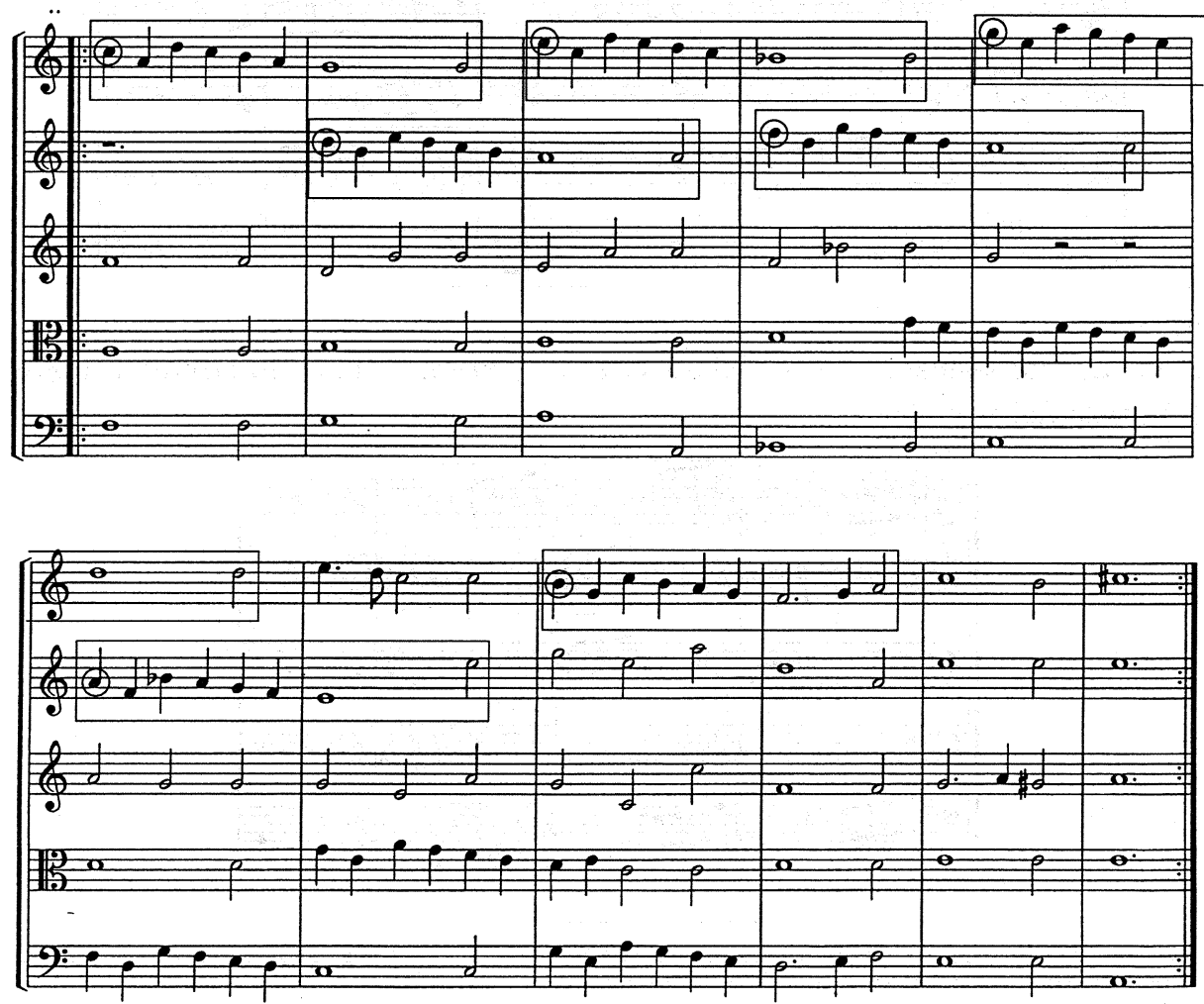
Primer 5

Johannes Thesselius: Neue liebliche Paduanen, Intraden und Galliarden (1609); XXIIII. Galliarda, tretji del

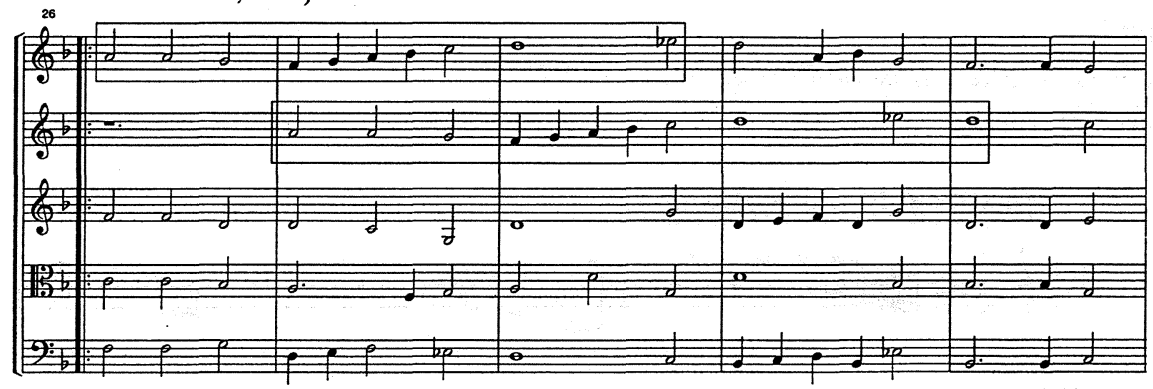

V začetku 17.stoletja se je $\mathrm{v}$ Italiji izoblikovala monodija, ki je dajala prednost zgornjemu glasu, vendar poudarjenega zgornjega glasu pri Thesseliusu še ne zasledimo. Podobno kot $\mathrm{v}$ Scheinovi zbirki plesov $\mathrm{z}$ naslovom Banchetto musicale, so tudi pri Thesseliusovi glasbi za inštrumentalni sestav plesi bili oblikovani $\mathrm{v}$ načinu polifonega moteta. ${ }^{39}$ Polifono vodenje glasov je kombiniral $z$ odseki, kjer je zaradi homoritmičnega gibanja vseh glasov nastopila vertikala. V njej zasledimo že povsem jasno postavljene akorde - največ je durovih, potem molovih, in tudi zmanjšanih kvintakordov, kot tudi sekstakordov in prehajalnih kvartsekstakordov. Pogosto ima Thesselius zvočno še zelo goste, $z$ neakordskimi toni prepletene odseke in prečja med glasovi kot rezultat linearnega vodenja glasov.

Variacijske povezave Intrade in Galliarde v smislu motivičnih začetkov so pri Thesseliusu skromne, saj se pojavijo le v začetnem taktu prve in druge suite. Zato je enotaktna variacijska povezava pri Thesseliusu rezultat slučaja in ne hotena rešitev kompozicije. Pri drugih avtorih variacijske suite je variacijska povezava bolj očitna in jo je potrebno razumeti v smislu Galliarde kot poplesa, za katero je bilo značilno, da je iz osnovnega dvodobnega ritma sledil tridobni, pri tem pa se glasbeni impulz ni spremenil (primer 6).

\section{Primer 6}

Paul Peuerl: Neue Padovan, Intrada, Däntz unnd Galliarda (1611)

Dantz in Galliarda, začetek ${ }^{40}$

c) Dantz

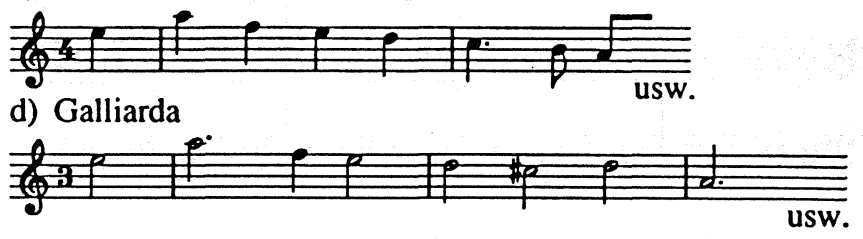

39 Diether de la Motte, Melodie, Kassel, Bärenreiter 1993, str. 225

40 Ibid., str. 223 
Poplesi so bili največkrat improvizirani del suitnih stavkov. Izjema je bil Posch, ki je poplese zaradi nereda, ki je vladal v zvezi $z$ izvedbami, izpisal ${ }^{41}$ (primer 7).

Primer 7

Isaac Posch: Musicalische Ebrenfreudt (1618)

a) Tanz III a 4

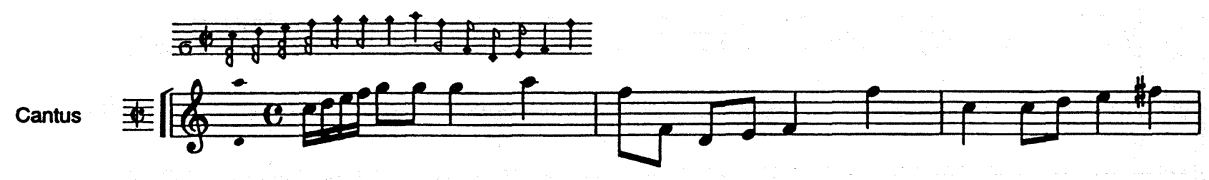

b) Proportio

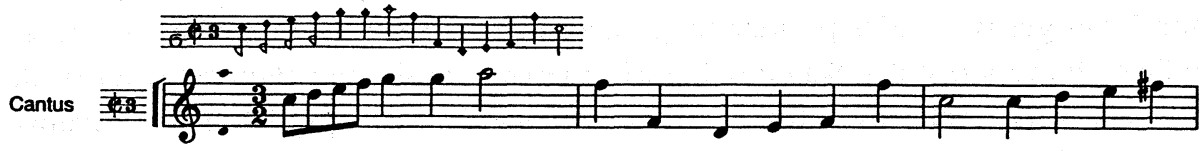

$\mathrm{V}$ peti Thesseliusovi suiti je opazna variacijska povezava Paduane in Intrade $\mathrm{z}$ motivom, ki nastopi med potekom skladbe (primer 8). Zanimivo je, da se motiv v obeh plesih giblje $\mathrm{v}$ istih glasovih: cantusu, quintavoxu in basusu. V Paduani ritmično in melodično nespremenjen nastopi štiri-krat, $v$ Intradi tri-krat, $v$ obeh plesih pa je tudi še spremenjen: v Paduani je sprememba melodična (a), v Intradi pa gre za razširitev motiva (b).

\section{Primer 8}

Johannes Thesselius: Neue liebliche Paduanen, Intraden und Galliarden (1609); a) XIII. Paduana, prvi del

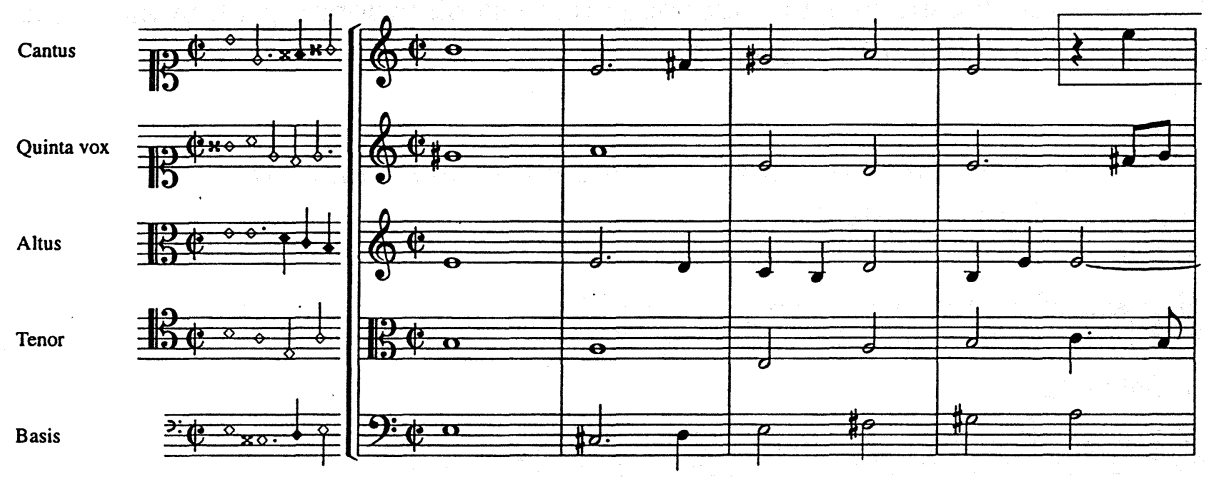

41 Metoda Kokole, Inštrumentalna zbirka Musicalische Ehrenfreudt (1618) skladatelja Isaaca Poscha, Muzikološki zbornik XXXII, Ljubljana, Oddelek za muzikologijo Filozofske fakultete 1996, str. 9. 
MUZIKOLOŠKI ZBORNIK • MUSICOLOGICAL ANNUAL XXXIV
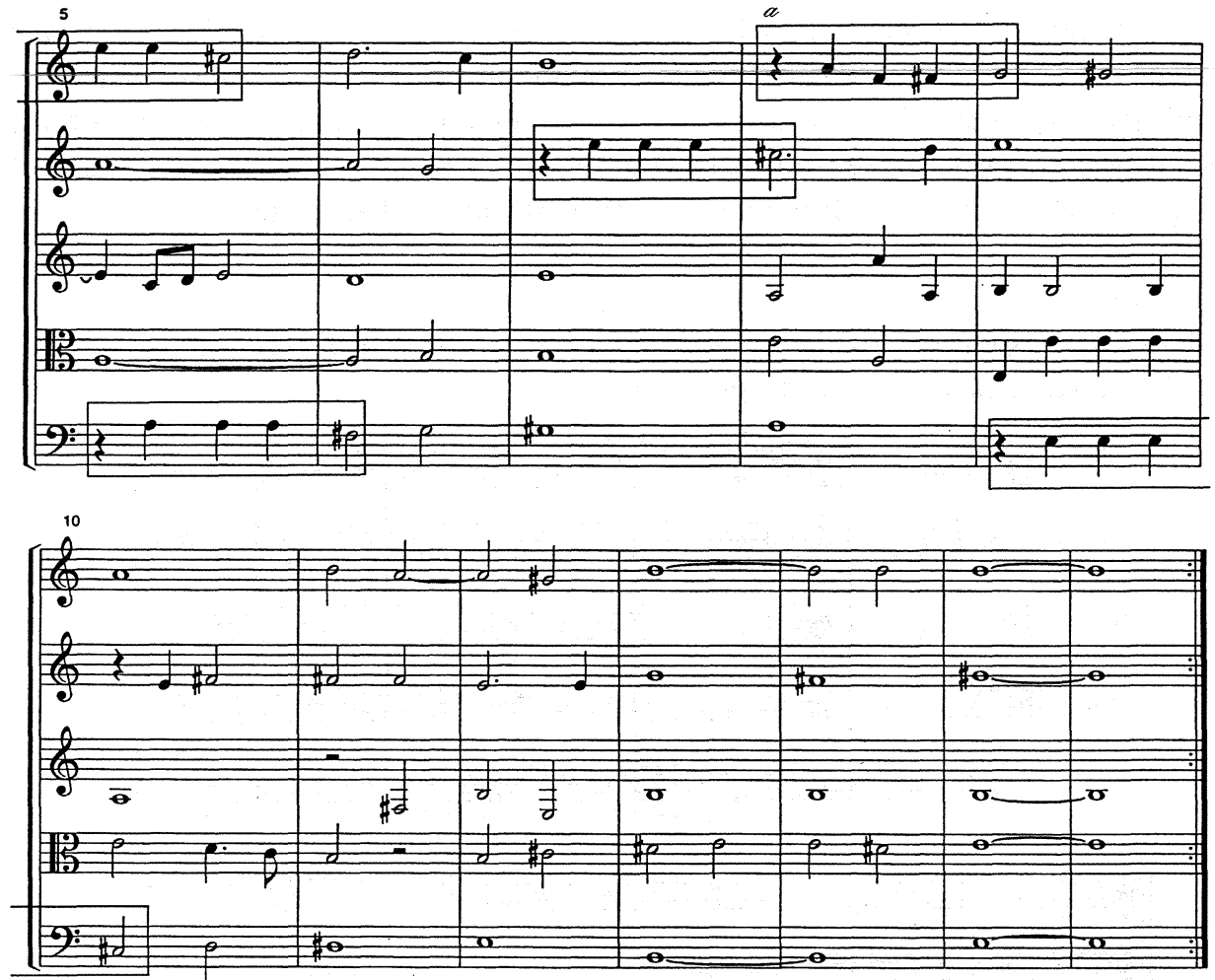

b) XIIII. Intrada, drugi del (takti 12-14)

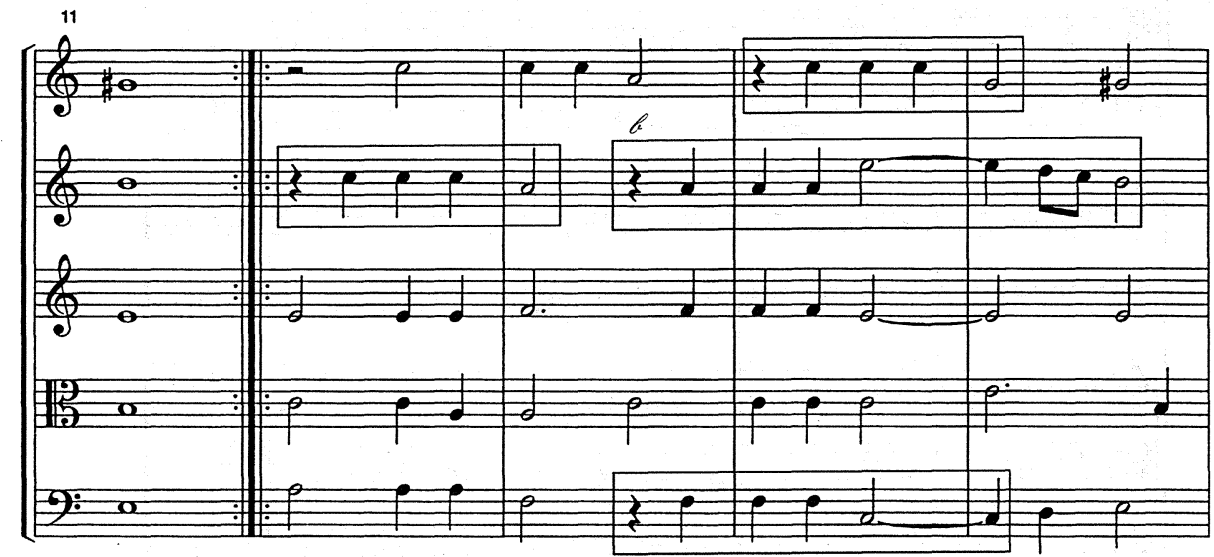

Posebej zanimiva je četrta Thesseliusova suita, kjer zasledimo variacijske povezave med Pavano in Galliardo v basovskem postopu. Na začetku Pavane je skladatelj vodil basovski glas $\mathrm{v}$ kvartah na petih tonih navzgor, $\mathrm{v}$ tretjem delu istega plesa pa 


\section{MUZIKOLOŠKI ZBORNIK • MUSICOLOGICAL ANNUAL XXXIV}

je kvarte ponovil na smeri navzdol. V Galliardi se ponovi le postop kvart navzgor (primer $9 \mathrm{a}, \mathrm{b}, \mathrm{c}$ ). Tematsko povezavo Paduane in Galliarde $\mathrm{v}$ četrti Thesseliusovi suiti omenjata, kot daleč najzgodnejši primer takšne tematska povezave in kot anticipacijo variacijske suite, tudi glasbena leksikona Die Musik in Geschichte und Gegenwart ${ }^{42}$ in The new Grove Dictionary of Music and Musicians. ${ }^{43}$

\section{Primer 9}

Johannes Thesselius: Neue liebliche Paduanen, Intraden und Galliarden (1609);

a) X. Paduana, začetek prvega dela

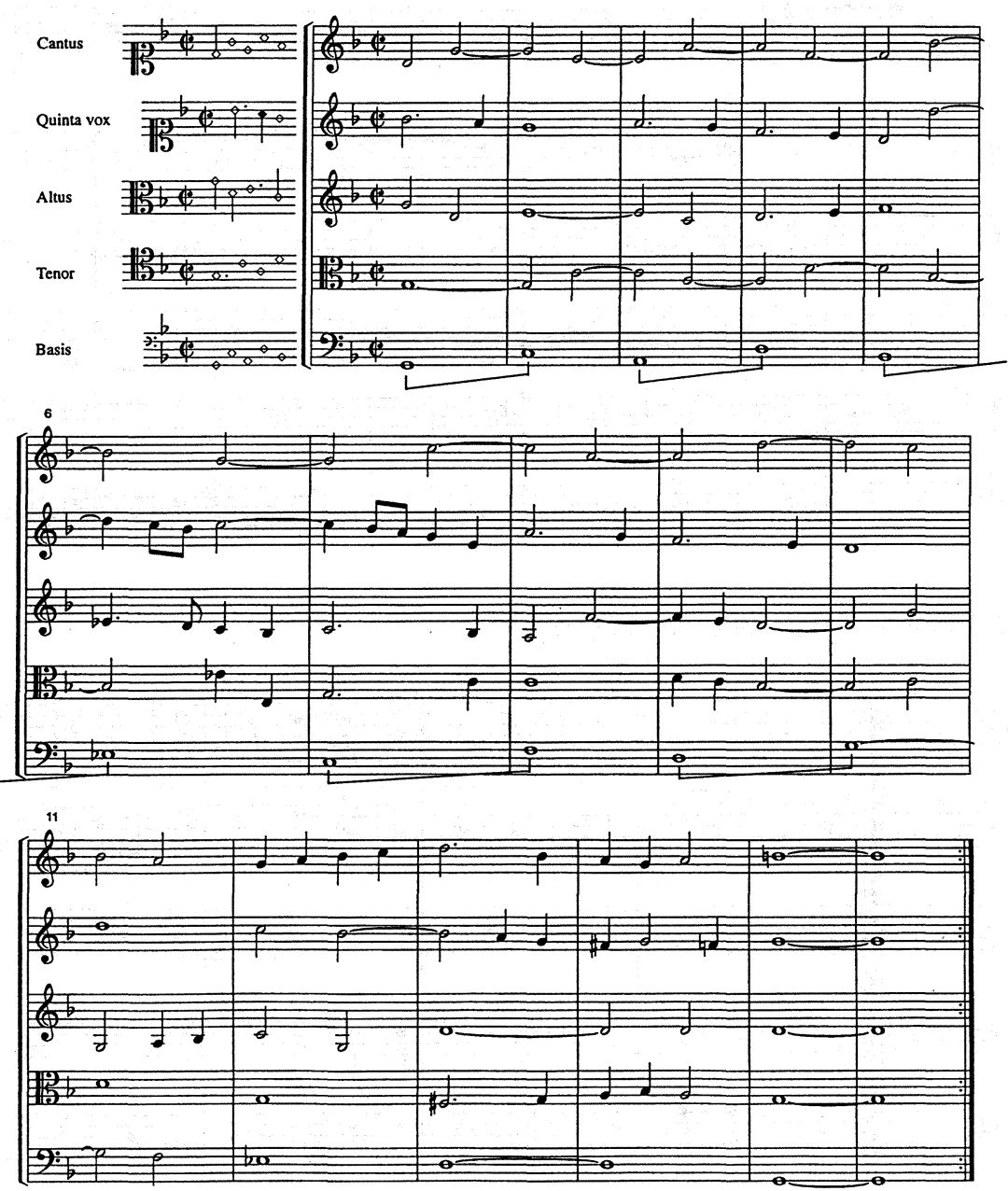

42 Die Musik in Geschichte und Gegenwart 13, Hrg. F. Blume, Kassel, Bärenreiter 1966, str. 330.

43 The new Grove Dictionary of Music and Musicians 18, Ed. S. Sadie, London 1980, str. 763. 
MUZIKOLOŠKI ZBORNIK • MUSICOLOGICAL ANNUAL XXXIV

b) X. Paduana, začetek tretjega dela
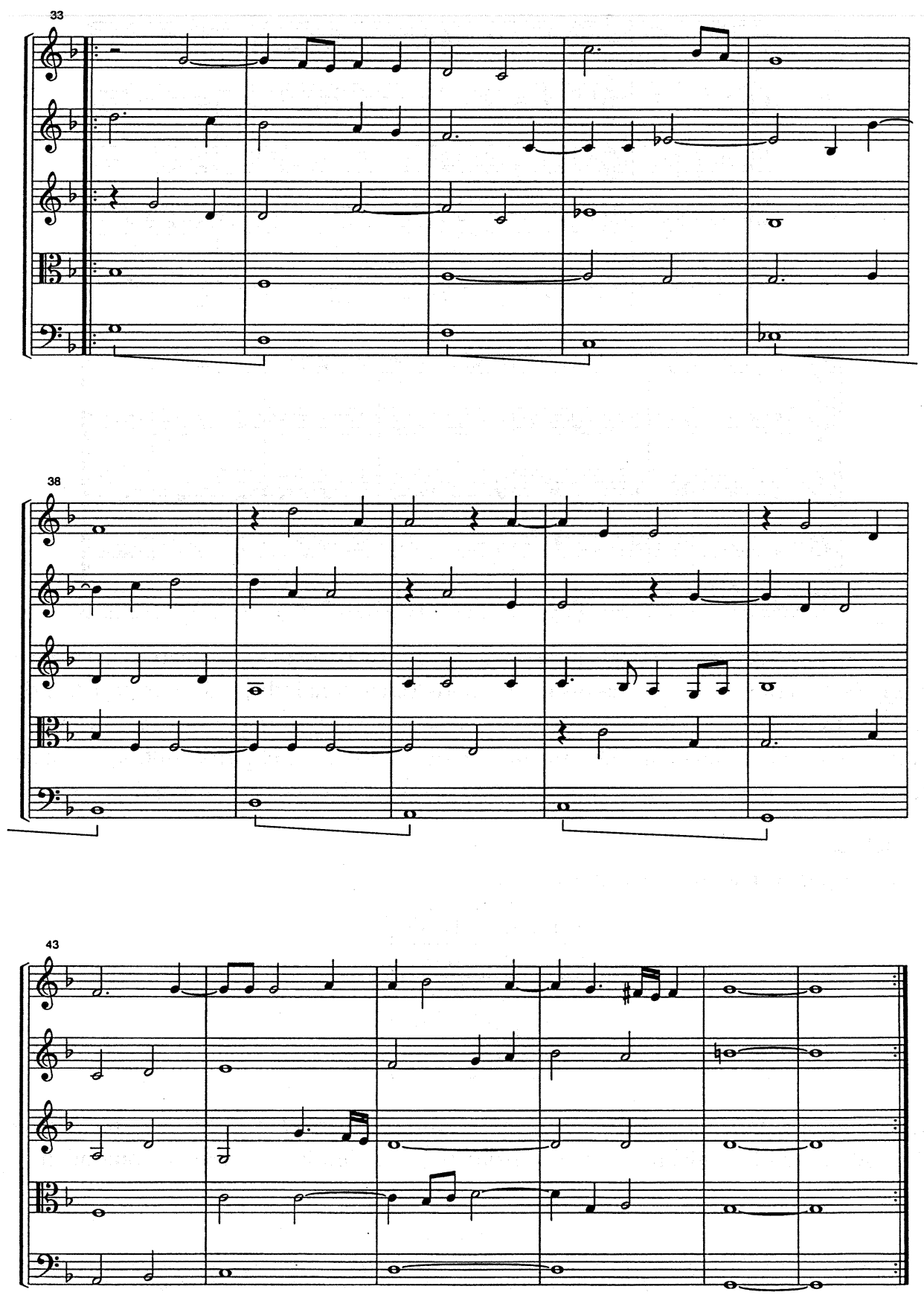
c) XII. Galliarda, začetek prvega dela

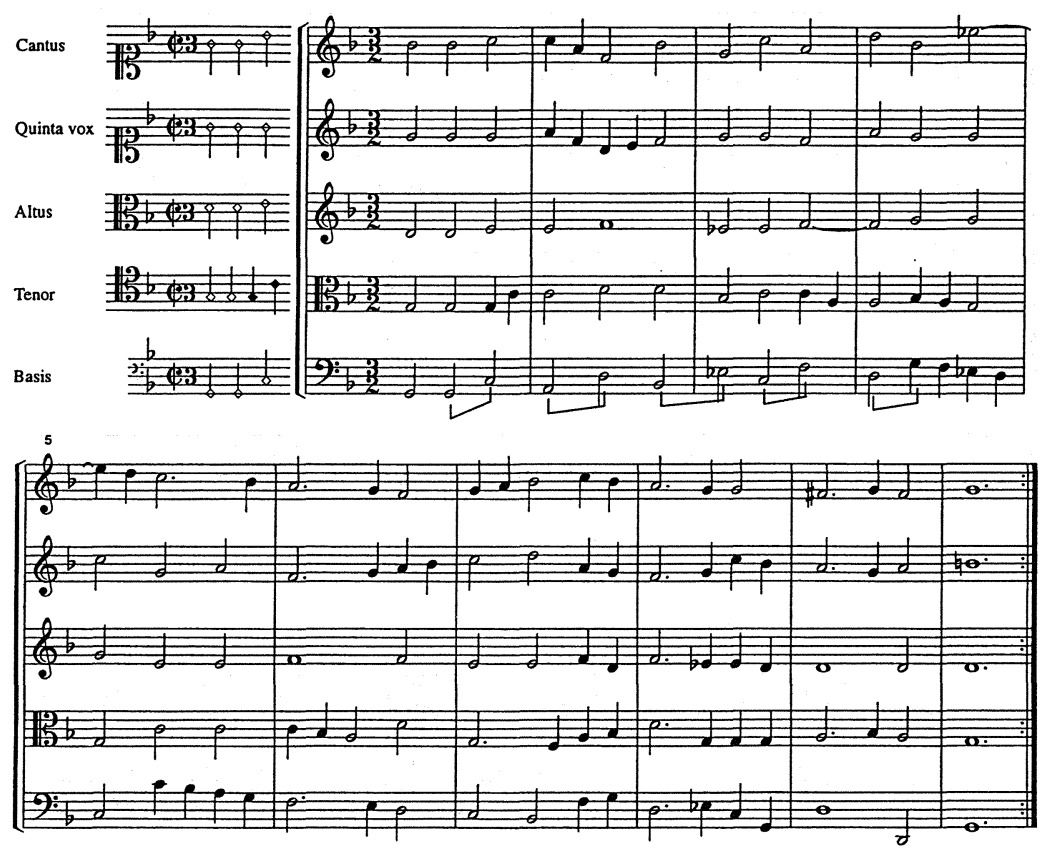

Thesseliusova zbirka ima tudi posebnost, s katero predstavlja anticipacijo svojega časa. Skladatelj si je zbirko zamislil kot ciklus suit v tonalnih parih, kar pomeni, da je cikel treh plesov $\mathrm{v}$ isti tonaliteti ${ }^{44}$ postavil še $\mathrm{v}$ tonalni odnos, $\mathrm{v}$ kvintno razdaljo $\mathrm{z}$ drugo suito, kar je značilno za baročno obdobje. Dobil je pet parov suit, kjer si z izjemo četrtega para, vsi sledijo v kvintnem odnosu v sledečem zaporedju ${ }^{45}$ (tabela 2).

Tabela 2

Tonalni pari $\mathrm{v}$ Thesseliusovi zbirki suit

\begin{tabular}{|l|l|}
\hline I. par & D -G \\
\hline II. par & d -g \\
\hline III. par & E -a \\
\hline IV. par & C -B \\
\hline V. par & C -F \\
\hline
\end{tabular}

Zanimiva je Thesseliusova formulacija "auff alle Modos", ${ }^{46} \mathrm{ki}$ nakaže, da je Thesselius imel $\mathrm{v}$ mislih različne tonske načine. Vendar je modos pomenil tudi

44 Podobno tudi Schein v uvodu svoje zbirke opozarja, da sta tonaliteta in razvrstitev posameznih stavkov v vsaki suiti enotni: "daß sie beides, in Tono und inventione einander fein respondieren", J. H. Schein, Sämtliche Werke, Hrg. A. Prüffer, Leipzig 1901, r. 1971.

45 Harald Kümmerling, Thesselius, Johannes, Die Musik in Geschichte und Gegenwart 13, Kassel, Bärenreiter 1966, str. 330. 
način sam, kot na primer "na različne melodije". Težko je določiti ali je govoril o enem ali drugem.

Thesselius je podobno kot drugi avtorji ansambelske glasbe na začetku 17. stoletja glasove poimenoval po naravnih vokalnih glasovnih legah, čeprav je v naslovu jasno zapisal, da je zbirko plesov namenil za igranje na različnih inštrumentih. ${ }^{47} \mathrm{Za}$ razliko od Poscha, ki je odstopal od tradicionalne kombinacije ključev, ${ }^{48}$ je Thesselius uporabil dve od štirih predpisanih kombinacij ključev za polifonijo. ${ }^{49}$ Kar 18-krat od 30 primerov je uporabil kombinacijo ključev, ki so ustrezali registom človeškega glasu (chiavi naturali: basovski f-ključ, tenorski c-ključ, altovski cključ in dva sopranska c-ključa) in 11-krat kombinacijo visokih ključev, ki so pomenili transpozicijo za terco navzdol (chiavette: baritonski f-ključ, altovski cključ, mezzosopranski c-ključ in dva violinska g-ključa). ${ }^{50}$ Kombinacija basovskega, tenorskega, altovskega in dveh violinskih ključev, ki jo je Thesselius v celi zbirki plesov uporabi samo enkrat (XVIII. Galliarda), ne spada med predpisane štiri. ${ }^{51}$ Glede na postavitev ključev je Thesselius plese svoje zbirke zapisal v naslednjih modusih $^{52}$ (tabela 3).

Tabela 3

Thesseliusovi modusi glede na postavitev ključev

\begin{tabular}{|l|l|}
\hline 1. suita & 1. modus (d) \\
\hline 2. suita & 1. transponirani modus (g) \\
\hline 3. suita & 2. transponirani modus (d') \\
\hline 4. suita & 2. transponirani modus (g) \\
\hline 5. suita & 3. (e) ali 4. (e) \\
\hline 6. suita & 3. transponirani (a; redek) ali 4. transponirani (a) \\
\hline 7. suita & 11. Glareanski modus (c) \\
\hline 8. suita & \\
\hline 9. suita & 12. Glareanski modus (c) \\
\hline 10 suita & 6. modus (f) \\
\hline
\end{tabular}

46 Beseda modos je $\mathrm{v}$ izvirniku pisana $\mathrm{v}$ latinici $\mathrm{z}$ razliko od drugega besedila, ki je $\mathrm{v}$ gotici, zato jo izpisujem $\mathrm{v}$ ležeči pisavi. $\mathrm{V}$ latinici so ponavadi, kot tudi $v$ našem primeru, tiskali tujke. Modus pomeni takt, ritem, napev, melodijo, tudi način. Fran Bradač, Latinski - slovenski slovar, Ljubljana, DZS 1980, str. 323.

47 "auff allerley Instrumenten zu gebrauchen mit fünff Stimmen componirt"

48 Metoda Kokole, Inštrumentalna zbirka Musicalische Ehrenfreudt (1618) skladatelja Isaaca Poscha, Muzikološki zbornik XXXII, Ljubljana, Oddelek za muzikologijo Filozofske fakultete 1996, str. 25.

49 P. Barbieri, Chiavette and Modal Transposition in Italian Practice (c. 1500-1837), Ricercare 3 (1991), str. 6.

50 Poleg chiavi naturali in chiavette še in contrabasso - nizka kombinacija ključev, ki je pomenila transpozicijo za terco navzgor in soprano accutissimo - najvišja kombinacija ključev, ibid., str. 6.

51 Bernhard Meier, Alte Tonarten, Kassel (etc.), Bärenreiter 1994, str. 182.

$52 \mathrm{~V}$ glasbi na prehodu iz 16. v 17. stoletje je odločitev za modalnost ali tonalitetnost problematična, oziroma nemogoča, zato je v analizi prisotno oboje. Glej tudi Metoda Kokole, Inštrumentalna zbirka Musicalische Ehrenfreudt (1618) skladatelja Isaaca Poscha, Muzikološki zbornik XXXII, Ljubljana, Oddelek za muzikologijo Filozofske fakultete 1996, str. 25, 26. 
Thesselius je zgornji glas ojačal z drugim sopranskim glasom - quintavoxom, glasova sta se imitacijsko dopolnjevala in večkrat križala. Podobno lahko tudi pri Poschu govorimo o dveh enakovrednih sopranskih glasovih (cantus in altus), ki ju zaradi registrske in glasbene izenačenosti, ne moremo razdvajati. ${ }^{53}$ Srednja dva glasova, altus in tenor, sta bila pri Thesseliusu zastopana enakovredno in pri tem ni opaziti, da bi bil tenor najpreprostejši glas $v$ smislu vodilnega glasu, kot je $\mathrm{v}$ Poschovi zbirki Ehrenfreundt. ${ }^{54}$ Medtem ko sta bila pomembna $v$ določenih suitah Isaaca Poscha oba krajna glasova, je podobno oblikovanje pri Thesselius opazno le v določenih odsekih.

$\mathrm{Z}$ analizo vokalne glasbe, predvsem $\mathrm{v}$ povezovanju $\mathrm{z}$ naukom o figurah, se je ukvarjalo veliko glasbenih teoretikov že v 17. stoletju (J. Burmeister, J. Lippius, M. Praetorius), medtem ko plesno glasbo viri redko omenjajo. Zato se $\mathrm{v}$ sedanjosti postavlja vprašanje, kako analizirati in uvrednotiti to vrsto glasbe. $S$ poskusom "zgodovinske analize" Thesseliusove glasbe $z$ vidika nauka o figurah, bi lahko dokazali soodvisnost vokalne in inštrumentalne glasbe v 17. stoletju. Za pravilno interpretacijo plesne glasbe bi bilo po mnenju Joan Rimmer nujno nadaljevati $\mathrm{z}$ analizo funkcionalnega aspekta plesov, saj je vsaka razlaga notnega zapisa plesov do neke mere odvisna od poznavanja plesnega gradiva. ${ }^{55}$ Podobno kot je bil nauk o figurah in navezovanje glasbe na retorični princip odločilnega pomena v vokalni glasbi, bi morali $\mathrm{v}$ plesni glasbi iskali navezavo, soodvisnost in prepletenost $\mathrm{s}$ plesno koreografijo.

Priloga št. 1

Johannes Thesselius: Neue liebliche Paduanen, Intraden und Galliarden (1609); Thesseliusovo posvetilo zbirke baronu Carlu Jörgerju

Dem Wolgebornen Herrn /// Herrn Carln Jörgern zu Tolleth / Köppach // vnd Stauff: Freyherrn auff Kreuspach: Herrn // zu Pernstein / Scharnstein vnd Walpersdorff: Erb= // landhofmeister inn Öesterreich ob der Enns mei= $/ /$ nem Grädigen vnnd Hochgebietten= // ten Herrn.

// Wolgeborner Ereyherr / Gnädiger // Herr / die herrliche kunst der Music*, welche ohn // allen zweyffel vnter andern Freyen künsten die // schönste vnd lieblichste ist / ob sie wolvon vilen // verachtet / so hat sie gleichwol entgegen ihre fautores vnd gönner /// wie zu beweisen ist an E. G. die bisshero sehr vildrauff gewendet /// vnd selbsten die edle kunst sehr wolverstehen. Weil ich dann mich // bisshero inn der kunst geubet / so hab ich dise meine neue geringfu= // gige Paduanen / Intraden vnnd / vn Galliarden / auff alle modos // (wie man sie

53 Metoda Kokole, Inštrumentalna zbirka Musicalische Ehrenfreudt (1618) skladatelja Isaaca Poscha, Muzikološki zbornik XXXII, Ljubljana, Oddelek za muzikologijo Filozofske fakultete 1996, str. 29.

54 Ibid., str. 13.

55 J. Rimmer, Allemande, Balletto and Tanz, Music and Letters 70 (1989), str. 226-227. 
pfleget von E. G. Tafel zu Musiciren) gesesst vnd // verfertiget. Solche verfertigung aber hab ich E. G. in dienstli=// cher geho:samgheit in offene truck dediciren vn zueignen wollen /// vngezweiffelter hoffnung / Sie werden / als liebhaber diser Hinli= // schen kunst / ernannte meine neuen Paduanen / Intraden vn Gal= // liarden / in iren schuss auffnemen / vnd in gnaden gefallen lassen /// auch hinfuro / wie bisshero / mein Gnädiger Herr vn Patron sein // vnnd bleiben. Datum im Schloss Aschach den 1. Septem. // Anno 1609.//

gehorsamer vnd dienstgeflissner// Johannes Thesselius, bestellter $\mathrm{Mu}=/ /$ sicus daselbsten.

* Ležeče so izpisane vse besede, ki so v originalu napisane v latinici.

Priloga št. 2

Johannes Thesselius: Neue liebliche Paduanan, Intraden und Galliarden (1609); število taktov in tri- ali štiri-delnost plesov

I. Paduana - 48 taktov; delitev ponavljajočih delov na 16,16,16 taktov, s tem, da je $v$ zadnjem delu vmesna sprememba metruma s tremi takti $(5,3,8$ taktov). II. Intrada - 33 taktov; 9,11,13 taktov. III. Galliarda -27 taktov, 9,2,9. Skupaj 108 taktov.

IIII. Paduana - 48; 16,16,16. V. Intrada - 33; 13,9,11. VI. Galliarda - 30; 11,11,8. Skupaj 111 taktov.

VII. Paduana - 48; $16,16,16$. VIII. Intrada - 33; 10,12,11. IX. Galliarda - 33; 10,11,12. Skupaj 114 taktov.

X. Paduana - 48; 16,16,16.

XI. Intrada - 29; 10,9,10.

XII. Galliarda - 31; 10,10,11. Skupaj 108 taktov.

XIII. Paduana - 48; 16,16,16. XIIII. Intrada - 34; 11,13,10. XV. Galliarda - 30; $10,10,10$. Skupaj 112 taktov.
XVI. Paduana - 48; 16,16,16.

XVII. Intrada - 35; 12,12,11.

XVIII. Galliarda - 39; 14,12,13.

Skupaj 122 taktov.

XIX. Paduana - 48; 16,16,16.

XX. Intrada - 33; 11,11,11.

XXI. Galliarda - 38; 12,13,13.

Skupaj 119 taktov.

XXII. Paduana - 48; 16,16,16.

XXIII. Intrada - 37; 11,13,13.

XXIIII. Galliarda - 37: 12,13,12.

Skupaj 122 taktov.

XXV. Paduana - 48; 16,16,16.

XXVI. Intrada - 41; 11,9,11,10.

XXVII. Galliarda - 39; $13,13,13$.

Skupaj 128 taktov.

XXVIII. Paduana - 48; 16,16,16.

XXIX. Intrada - 36; 13,10,13.

XXX. Galliarda - 37; 14,12,11.

Skupaj 121 taktov. 
Priloga št. 3

Johannes Thesselius: Neue liebliche Paduanan, Intraden und Galliarden (1609); akordični začetki in zaključki posameznih delov plesov

\begin{tabular}{|l|l|l|l|}
\hline & Paduana & Intrada & Galliarda \\
\hline 1. suita - D & D-D; C-A; F-D & D-D; d-A; C-D & D-D; A-A; D-D \\
\hline 2. suita - G & G-D; d-A; B-G & g-G; D-D; C-G & g-G; B-D; g-G \\
\hline 3. suita - d & d-D; A-A; D-D & d-D; A-A; a-D & a(d)-D; F-A; C-D \\
\hline 4. suita - g & g-G; g-D: g-G & g-G; g-D; B-G & g-G; g-D; B-G \\
\hline 5 suita - E & E-E; a-A; H-E & E-E; a-A; E-E & e-E; a-C; a-E \\
\hline 6. suita - a & a-A; a-D; A-A & a-A; d-E; a-A & a-A; d-C; F-A \\
\hline 7. suita - C & C-C; G-G; C-C & C-C; F-F; G-C & C-C; a-F; F-C \\
\hline 8. suita - B & B-B; g-F; F-B & B-B; F-d; F-B & B-B; d-F; F-B \\
\hline 9. suita - C & C-C; G-G; C-C & C-C; A-E; F-G; G-C & C-C; d-A; C-C \\
\hline 10. suita - F & F-F; d-C; F-F & F-F; F-C; F-F & F-F; F-C; F-F \\
\hline
\end{tabular}

\section{Johannes Thesselius and bis Collection of Dances for Five-Part Instrumental Ensemble}

\section{Summary}

The collection Neue liebliche Paduanen, Intraden und Galliarden auff allerley Instrumenten zu gebrauchen mit fünff Stimmen componirt, by Jobannes Thesselius is noted in musical bistory as the earliest work shaped in the sense of variation suites for instrumental ensemble. It contains thirty dances, distributed in ten cycles with a uniform sequence of three dances: Paduana - Intrada - Galliarda. It was printed in the year 1609, for the publisher and printer Paul Kauffmann in Nürnberg. The dances in Thesselius's suite are linked up by the same tonality, whereas the variational shaping is in some places merely indicated. The variation suite for instumental ensemble or, in short the ensemble variation suite was a shortlived phenomenon in the Austro-German music at the beginning of the 17 th centu$r y$, or more precisely between 1609 and 1616 when the four dance collections by their respective authors - Johannes Thesselius, Paul Peuerl, Jobann Hermann Schein and Isaac Posch - were issued.

As the beginner of the ensemble variation suite, of which it is characteristic that its movements must be at least partly related by identical motivic parts or beginnings, we regard Paul Peuerl (1611), who was, like Thesselius, active on the present-day 


\section{MUZIKOLOŠKI ZBORNIK • MUSICOLOGICAL ANNUAL XXXIV}

territory of Austria. Yet its first origins can be traced already in Thesselius, notably in the first two suites (the linkage of the beginning of the Intrada and the Galliarda), in the fourth one (the linkage of the bass sequence in the Paduana and the Galliarda), and in the fifth one (the linkage of one motif in the Intrada and the Galliarda).

His suites had already all the characteristics of instrumental music. The dominant principle in Thesselius's shaping of music was work on motifs which be mostly rhythmically reiterated. Most commonly the motif is in all parts at the same time rbythmically identically reiterated or by way of imitation passed on through all parts. Not so frequent were sequential reiterations of the motif or longer imitations. Like in Schein's collection of dances, entitled Banchetto musicale, in Thesselius's music for instrumental ensemble the dances were also designed in the manner of a poliphonic motet. He combined the polyphonic leading of parts with segments where the homo-rbytbmic leading of all parts gave a vertical result. Thesselius bas frequently as regards sound still very dense segments, interwoven with non-chordal tones, and as a result of the linear leading of parts.

Thesselius's life was mysterious. We know neither the years of his birth or death, nor any data about the composer's musical education. Thesselius's collection of songs for instrumental ensemble and the dedication contained in it are thus the only two sources about his musical activity and creativeness. 